\title{
Do we provide dental treatment out-of-hours?
}

\author{
Out-of-hours dental services: a survey of current provision in the United Kingdom R. Anderson and D. W. Thomas \\ Br Dent J 2000; 188: 269-274
}

\section{Objective}

To describe the variety of arrangements for providing out-ofhours dental care in the UK.

\section{Design}

A telephone interview survey of health authorities and health boards.

\section{Setting}

United Kingdom.

\section{Subjects}

104 health authority contacts, usually consultants in dental public health, dental advisers or others in a position to describe the local dental service arrangements.

\section{Results}

At weekends, 25 authorities have no formal dental care arrangements for unregistered patients, 55 have separate arrangements for registered and unregistered patients, and 44 have 'universal access' arrangements - for anyone in an area, regardless of their registration status. On weekday nights over two-thirds (82/124) of UK health authorities have no formal arrangements for unregistered patients. Where there are separate 'safety-net' services intended for unregistered patients only they are usually (in 48 of 55 authorities) emergency treatment sessions. A fifth of authorities reported planned changes to their local out-of-hours arrangements, including the introduction of telephone triage, and moves to make care available at more times, to more people or from centralised premises.

\begin{abstract}
Conclusions
There is extremely wide geographical variation in the organisation of out-of-hours dental services provided in the United Kingdom. In many parts of the UK there are no formal out-of-hours care arrangements for unregistered patients, even at weekends. This unequal provision will mean inequitable access for many unregistered patients. With increasing demands from a growing unregistered population, and various government initiatives to make primary care services more integrated and accessible, the highly fragmented pattern of provision in many areas may no longer be acceptable.
\end{abstract}

\section{In brief}

- This study describes the variety of arrangements for providing out-of-hours dental care in health authorities across the UK.

- It particularly highlights the lack of formal arrangements for unregistered patients in many areas.

- In the light of recent primary care initiatives to improve access to care, and the growing numbers of unregistered patients, the wide geographical variations in service provision described may become increasingly unacceptable.
$\mathrm{O}_{\mathrm{h}}^{\mathrm{n}}$ ne of the highest priorities of any healthcare system is to ensure that those in the population who need emergency care receive it promptly, efficiently and equitably. Indeed this is one of the main aims of the Government's modernisation of the NHS. ${ }^{1}$

Successive surveys of oral health of the UK population show an improving picture with regard to caries' prevalence in all age cohorts yet a significant proportion of the population does not regularly access dental services. The inevitable consequence of this, particularly in areas of high need, is reliance upon emergency and out-of-hours services. This often manifests itself through inappropriate access to medical or A\&E services.

This paper reports a timely survey of the availability of out-of-hours dental services in the UK with a particular emphasis on services provided for unregistered patients. A good response rate from health authorities was achieved. Given the current political imperative with respect to out-of-hours services it was surprising that 25 out of the 124 health authorities/boards responding admitted to having no formal out-of-hours dental arrangements for non-registered patients even at weekends. On the other hand some health authorities were found to have very well organised provision. Given the sheer numbers of unregistered patients this would indicate that a significant proportion must be finding great difficulties in obtaining out-of-hours services. It would appear from the findings of this research that in terms of the availability of emergency services much depends on where you live. This post-coded availability is of course counter to Government policy.

The authors quite rightly point out the limitations of using semi-structered conversational interviews in a complex area like the provision of emergency dental services. Notwithstanding this, the paper provides a very useful baseline of the current availability of services which should be noted by policy decision-makers. In this respect it would be useful for the data to be made available by region.

There is already evidence that the introduction of personal dental services in some parts of the country has radically improved the availability of emergency services. Further developments like the role out of NHS Direct and its use for accessing dental care, together with the impact of the recently announced Dental Access Centres throughout England, ${ }^{2}$ points to the need for further research to examine any improvement in the current inequalities in access demonstrated by this paper.

\section{Tony Jenner}

Consultant in Dental Public Health Cheshire \& Wirral Health Authorities

1 Department of Health. The New NHS: Modern, Dependable. London: Stationery Office, 1997 Cm3807.

2 Department of Health. Easier Access to NHS Dentists. Press Release 2000/0006. London, January 5th 2000. 